\title{
A case of Evans syndrome associated with autoimmune thyroiditis
}

\begin{abstract}
Introduction: Evans syndrome is the occurrence of immune-mediated thrombocytopenia in the conjunction with autoimmune hemolytic anemia (AIHA). On the other hand, autoimmune thyroiditis is the presence of antibodies directed to thyroid peroxidase, thyroglobulin and thyroid stimulating hormone receptor. The association of Evans syndrome with hypothyroidism or autoimmune thyroiditis is extremely rare.

Case: We present an 8-year-old boy as the first such case in pediatric population diagnosed with Evans syndrome and neutropenia associated with autoimmune hypothyroidism.

Conclusion: As autoimmune diseases can occur simultaneously, we emphasize the need to perform appropriate investigations in patients with autoimmune cytopenias.
\end{abstract}

Keywords: evans syndrome, autoimmune hemolytic anemia, hashimoto's thyroiditis, hypothyroidism, neutropenia
Volume 6 Issue 4 - 2018

\author{
Ehab Hanafy,' Khaled Alanazi, ${ }^{2}$ Mashael \\ Alanazi, ${ }^{2}$ Ebtesam Alanazi, ${ }^{2}$ Nazim Faisal,' \\ Gihan Mahmoud' \\ 'Prince Sultan Oncology Center, King Salman Armed Forces \\ Hospital, Kingdom of Saudi Arabia \\ 2Department of Pediatric, King Salman Armed Forces Hospital, \\ Kingdom of Saudi Arabia
}

Correspondence: Ehab Hanafy, Prince Sultan Oncology Center, King Salman Armed Forces Hospital, Tabuk 100 ,

Kingdom of Saudi Arabia, Email ehab.hmahmoud@gmail.com

Received: July 09, 2018 | Published: August 08, 2018

\section{Introduction}

Evans syndrome is characterized by thrombocytopenia that occurs at the same time with direct Coombs positive autoimmune hemolytic anemia. ${ }^{1}$ The exact etiology is unclear, however, the presence of autoantibodies directed towards red blood cells, platelets and neutrophils is the hallmark of the disease. ${ }^{2}$ The natural course of this disease is chronic and relapsing and even with aggressive management, it is still of poor outcome. Management of Evans syndrome is still challenging, steroids being the first line of treatment can occasionally cause remission, however exacerbations and relapse still do occur. Other lines of treatment include immunoglobulins, rituximab, cyclosporine and splenectomy. ${ }^{3-5}$ Stem cell transplantation has been used and results are not reassuring. ${ }^{6}$

On the other hand, Hashimoto thyroiditis is the most common cause of immune-mediated hypothyroidism where antibodies cause destruction of the thyroid cell. ${ }^{7}$ The natural course of the disease can be subclinical and can even be detected on routine screening but can progress to more advanced disease. The management of choice is thyroid hormone replacement that is taken orally for life. Early detection of the disease and institution of thyroxine therapy will eventually lead to an excellent prognosis with lesser complications and morbidities.

\section{Case presentation}

This is an 8year old Saudi male patient presented with an acute onset of severe pallor, fatigue and poor oral intake. There was no fever, oxygen saturation was $97 \%$ room air, blood pressure was normal for age (115/70) and there was no tachycardia (65beats/min). Both parents are non-consanguineous and have no medical history of concern. The child had no history of hypertension, diabetes or other conditions of medical significance, no history of previous surgeries and no history of drug allergies. Developmental history is compatible with his age and vaccination is up to date.

On clinical examination, the child looks pale, not jaundiced nor cyanosed, non-dysmorphic, there was no organomegaly, ENT examination was unremarkable, no skin rash or any sign of bleeding, initial neurologic examination was unremarkable with normal motor power, sensations and reflexes. Subsequently, he was admitted at the hospital and diagnosed as coombs positive autoimmune hemolytic anemia (Table 1).

He started on full supportive measures including intravenous immunoglobulins (IVIG) $1 \mathrm{gm} / \mathrm{kg}$ per day for 2 doses, and received a least incompatible blood transfusion, after which the child started to improve gradually with full activity. His general condition was normal and started to follow up regularly at the hematology clinic.

During the initial 6months of follow up, his disease showed frequent relapses and remissions and he presented several times with thrombocytopenia (platelets count ranging from 10-50 x103/ $\mu \mathrm{l})$ and neutropenia (ANC of 0.2-0.8) (Evans syndrome) which were attributed to his autoimmune hematologic disorder after exclusion of other causes by bone marrow aspirate that showed normal marrow with mild erythroid hyperplasia and flow cytometric immunophenotyping of bone marrow cells that revealed no evidence of immature CD34+ cell population, normal B-Cell population with polyclonal light chain expression, most importantly there was no evidence of an immature B-Cell population (CD19+,CD10+), no evidence of immature T-Cell population $(\mathrm{CD} 3+, \mathrm{TdT}+)$ or T-Cell activation.

He received several times IVIG at $1 \mathrm{gm} / \mathrm{kg} / \mathrm{dose}$ for 2 days and received once oral prednisolone at $2 \mathrm{mg} / \mathrm{kg} /$ day for $1 \mathrm{month}$ followed by tapering with good transient response and negative coombs test.

Few months later, the child presented with fatigue, significant weakness, laziness and remarkable change in behavior, he was thoroughly investigated and was found to have significant hypothyroidism (Table 2). The child was referred to an endocrinologist who started him on L-thyroxin that resulted in marked improvement of his general condition. Nevertheless, he was still suffering of frequent relapses in the form of pancytopenia that have temporarily response on steroids (short courses of oral prednisolone $4 \mathrm{mg} / \mathrm{kg} / \mathrm{day}$ for 4 days) and IVIG.

We further investigated the child when we requested anti-thyroid antibodies that showed a positive result confirming the diagnosis of autoimmune thyroiditis (Hashimoto's thyroiditis) (Table2). At that time, we decided to start him on anti-CD20 monoclonal antibody (Rituximab) as a second line of management after IVIG and steroid failure. 
Table I shows the laboratory tests done at initial presentation

\begin{tabular}{|c|c|c|}
\hline Laboratory item & Value & Reference value \\
\hline Hemoglobin & $3.5 \mathrm{~g} / \mathrm{dl}$ & $|1.5-| 4 g / d \mid$ \\
\hline Platelets & $163 \times 10^{3} / \mu 1$ & $|80-400| 0^{\wedge} 3 / \mu \mid$ \\
\hline Absolute neutrophils & 1.5 & $2.0-8.0$ \\
\hline Reticulocyte count & 6.1 & $0.5-2.5$ \\
\hline G6PD & negative & negative \\
\hline Anti-nuclear antibody & 7.6 units & Less than 20units \\
\hline Anti-ds-DNA antibody & $25.91 \mathrm{U} / \mathrm{ml}$ & Less than $2001 \mathrm{U} / \mathrm{ml}$ \\
\hline $\mathrm{C} 3$ & $0.7 \mathrm{~g} / \mathrm{l}$ & $0.9-1.8 \mathrm{~g} / \mathrm{I}$ \\
\hline $\mathrm{C} 4$ & $0.2 \mathrm{~g} /$ & $0.1-0.4 g / /$ \\
\hline $\mathrm{LDH}$ & $350 u / l$ & $<150 u / \mid$ \\
\hline Direct antiglobulin test & Strongly positive & negative \\
\hline $\begin{array}{l}\text { Virology screening } \\
\text { including (EBV, CMV, } \\
\text { hepatitis, HIV) }\end{array}$ & negative & negative \\
\hline
\end{tabular}

Table 2 shows the laboratory tests done at follow up

\begin{tabular}{lll}
\hline Laboratory item & Value & Reference value \\
\hline TSH & $150 \mathrm{mlu} / \mathrm{l}$ & $0.52-5.08 \mathrm{mlu} / \mathrm{l}$ \\
T3 & $0 \mathrm{pg} / \mathrm{ml}$ & $2.3-4.2 \mathrm{pg} / \mathrm{ml}$ \\
T4 & $0.15 \mathrm{ng} / \mathrm{dl}$ & $0.89-1.76 \mathrm{ng} / \mathrm{dl}$ \\
Cortisol & $9.95 \mu \mathrm{g} / \mathrm{dl}$ & \\
ACTH & $67.34 \mathrm{pg} / \mathrm{mL}$ & $7.2-63.3 \mathrm{pg} / \mathrm{mL}$ \\
Anti-thyroglobulin antibodies & $>500 \mathrm{IU} / \mathrm{ml}$ & $<601 \mathrm{U} / \mathrm{ml}$ \\
\hline
\end{tabular}

He received 4 doses of Rituximab $\left(375 \mathrm{mg} / \mathrm{m}^{2}\right.$ weekly for 4 week) which resulted in marked and sustained improvement of his laboratory blood works and had a marvelous improvement effect on his general condition and quality of life.

The child is currently in good condition with no hematologic manifestations, thyroid function is in good control with daily oral thyroxine and he is under regular monthly follow up at the hematology and endocrinology clinics. No evident relapses were recorded for 6 months of follow up.

\section{Discussion}

To our knowledge, the case summarized above is the first reported case with combination of Evans syndrome and Hashimoto's thyroiditis in pediatric age group.

Evans syndrome has been reported before to be associated with multiple immune and non-immune disorders. Costallat et al., ${ }^{8}$ described an association in a patient with severe manifestation of multi-systemic systemic lupus erythematosus. ${ }^{8}$ While in one review by Michel et al.,9 Evans syndrome was associated with systemic lupus, lymphoproliferative disorders, and common variable immunodeficiency in $50 \%$ of patients. ${ }^{9}$

Furthermore, few cases with Evans syndrome have been reported to occur in patients with variable underlying disorders, for instant, insulin-dependent diabetes mellitus ${ }^{10}$ Hodgkin lymphoma, ${ }^{11}$ coeliac disease $^{12}$ and autoimmune hepatitis. ${ }^{13}$

Only four cases with an association of Evans syndrome and Hashimoto's thyroiditis were found in the literature and have been described solely in adult patients. ${ }^{14-17}$

On the other hand, thyroid abnormalities could be a presentation in different non-endocrine autoimmune disorders such as rheumatoid arthritis, systemic lupus erythematosus, polyarthritis, Crohn disease and myasthenia gravis. Few recent reports confirm the association with autoimmune hematologic diseases as pernicious anemias, hemolytic anemias and idiopathic thrombocytopenic purpura. ${ }^{18}$

Polyglandular autoimmune syndromes are rare immune disorders characterized by the coexistence of at least two endocrine gland insufficiencies with possible occurrence of non-endocrine immune disorders. Meanwhile our patient had no other endocrinal manifestation that could raise the possibility of the described syndrome. ${ }^{19}$

The optimal management of this association necessitates a multidisciplinary team approach. We managed our patient through a team including a pediatrician, endocrinologist and hematologist as better communication between health care staff will facilitate early detection of any complication and subsequent management. Steroids and IVIG have been tried for our patients but were always associated with transient effects. Second line therapy includes immunomodulating agents, our patient was started successfully on Rituximab (an anti CD20 monoclonal antibody that is approved for treatment of B-cell lymphomas) and that has been tried in refractory cases of Evans syndrome. Primary results were reassuring with normalization of the laboratory results, and the patient is currently following up regularly in a good general condition.

\section{Conclusion}

Every effort should be done to thoroughly investigate autoimmune disorders that may affect a specific organ in any case that present with immune mediated hematologic condition. This will assist in early detection and management of such conditions to avoid adverse events that might alter the course of the disease and quality of life.

\section{Acknowledgements}

None.

\section{Consent for publication}

Written informed consent was obtained from the patient's legal guardian for publication of this case report.

\section{Funding}

The author(s) received no financial support for the research, authorship, and/or publication of this article.

\section{Conflict of interest}

The author(s) declared no potential conflicts of interest with respect to the research, authorship, and/or publication of this article. 


\section{References}

1. Jaime-Pérez JC, Guerra-Leal LN, López-Razo ON, et al. Experience with Evans syndrome in an academic referral center. Rev Bras Hematol Hemoter. 2015;37(4):230-235.

2. Wang W, Herrod $\mathrm{H}$, Pui $\mathrm{CH}$, et al. Immunoregulatory abnormalities in Evans syndrome. Am J Hematol. 1983;15(4):381-390.

3. Blanchette VS, Kirby MA, Turner C. Role of intravenous immunoglobulin G in autoimmune hematologic disorders. Semin Hematol. 1992;29(3 Suppl 2):72-82.

4. Galor A, O'Brien T. Rituximab treatment for relapsed autoimmune hemolytic anemia in Evans syndrome. Int J Hematol. 2003;78(4):335-336.

5. Janić D, Krivokapić-Dokmanović L, Jovanović N, et al. Glucocorticoidresistant Evans' syndrome successfully controlled with low-dose cyclosporine. Int J Clin Pharmacol Ther. 2011;49(10):622-625.

6. Raetz E, Beatty PG, Adams RH. Treatment of severe Evans syndrome with an allogeneic cord blood transplant. Bone Marrow Transplant. 1997;20(5):427-429.

7. Tomer Y, Huber A. The etiology of autoimmune thyroid disease: a story of genes and environment. J Autoimmun. 2009;32(3-4):231-239.

8. Costallat GL, Appenzeller S, Costallat LT. Evans syndrome and Systemic Lupus Erythematosus: Clinical presentation and outcome. Joint Bone Spine. 2012;79(4):362-364

9. Michel M, Chanet V, Dechartres A, et al. The spectrum of Evans syndrome in adults: new insight into the disease based on the analysis of 68 cases. Blood. 2009;114(15):3167-3172.

10. Franklin VL, Torrance T, Peebles M, et al. Life-threatening autoimmunity with diabetes: management with an insulin pump. Pediatr Diabetes. 2003;4(3):151-154.
11. Keung YK, Cobos E, Bolanos-Meade J, et al. Evans syndrome after autologous bone marrow transplant for recurrent Hodgkin's disease. Bone Marrow Transplant. 1997;20(12):1099-1101.

12. Yarali N, Demirceken F, Kondolat M, et al. A Rare Condition Associated with Celiac Disease: Evans Syndrome. J Pediatr Hematol Oncol. 2007;29(9):633-635.

13. Jarasvaraparn C, Gremse DA. Commentary: Association of autoimmune hepatitis and Evans syndrome in children. $J$ Pediatrics \& Pediatr Med. 2017;1(1):17-19.

14. Koti K, Thumma RR, Nagarajan S, et al. Hashimoto's thyroiditis associated Evans syndrome: A rare case report on the clustered autoimmune disease triad. Indian J Endocrinol Metab. 2013;17(4):736-739.

15. Kang MY, Hahm JR, Jung TS, et al. A 20-year-old woman with Hashimoto's thyroiditis and Evans' syndrome. Yonsei Med J. 2006;47(3):432-436.

16. Hennemann $\mathrm{HH}$, Klöss A. Autoimmune haemolytic anaemia, thrombocytopenia and thyroiditis: An immunopathological triad. Dtsch Med Wochenschr. 1978;103(14):609-612.

17. Oh HJ, Yun MJ, Lee ST, et al. Evans syndrome following long-standing Hashimoto's thyroiditis and successful treatment with rituximab. Korean J Hematol. 2011;46(4):279-282.

18. Lio S, Albin M, Girelli G, et al. Abnormal thyroid function test results in patients with Fisher-Evans syndrome. $J$ Endocrinol Invest. 1993;16(3):163-167.

19. Betterle C, Lazzarotto F, Presotto F. Autoimmune polyglandular syndrome Type 2: The tip of an iceberg. Clin Exp Immunol. 2004;137(2):225-233. 